\title{
Chronic Stimulation of the Left Vagus Nerve: Cognitive Motor Effects
}

\author{
Beverley M. Clarke, A.R.M. Upton, Helene Griffin, Debbie Fitzpatrick and \\ Marijane DeNardis
}

\begin{abstract}
Background: Early studies of cognitive motor control have shown deficits in complex reaction time tests of epileptic subjects. The purpose of this efficacy study was to determine whether chronic (28 months) stimulation of the left vagus nerve (VNS) to control seizures increased these deficits in 6 epileptic subjects with intractable complex partial seizures. Methods: Subjects were assessed for simple reaction time, Test $\mathrm{A}$, and subsequent Tests $\mathrm{B}$ and $\mathrm{C}$ which involved more complex cognitive strategies. Tests were done pre-operatively (S1) and at intervals, 6-8 weeks (S2-S3), and at 6 month intervals (S4-S6) over a 28 month period. Data were collected and collated on an Apple II E computer (Apple, Cupertino CA. U.S.A.) and on electronic switch pad. Data were analyzed using a repeated measures analysis of covariance technique with 2 within subject factors, day, and time of day. Results: 2/11 cognitive measures showed a statistically significant difference. Error rate associated with Test A (simple reaction time) significantly decreased for the factor of day (repeated visits) $\mathrm{p}=.01$. For Test $\mathrm{C}$, error rates decreased in the afternoon $(\mathrm{p}=.03$ ). This test involved the subjects ability to respond quickly to one signal while simultaneously ignoring a second signal. Data analysis of the covariate showed that the effects of VNS are weak in comparison to baseline differences and the frequency of nerve stimulation negatively predicts the number of wrong errors. High frequency stimulation results showed fewer errors than low frequency stimulation $\mathrm{T}=-2.31, \mathrm{p}=.03$. Conclusion: Chronic stimulation of the left vagus nerve to control seizure activity does not impair cognitive motor control.
\end{abstract}

\begin{abstract}
RÉSUMÉ: La stimulation chronique du nerf vague gauche: effets moteurs cognitifs. Introduction: Des études préliminaires du contrôle moteur cognitif ont montré des déficits dans les épreuves du temps de réaction complexe des sujets épileptiques. Le but de cette étude d'efficacité était de déterminer si la stimulation chronique (28 mois) du nerf vague gauche (SNV) pour contrôler les crises d'épilepsie augmentait ces déficits chez 6 épileptiques qui avaient des crises partielles complexes résistantes au traitement. Méthodes: Le temps de réaction simple a été évalué chez les sujets, test $\mathrm{A}$, et on a ensuite procédé à des tests impliquant des stratégies cognitives plus complexes, les tests B et C. Les tests étaient faits avant l'intervention (S1) et à intervalles de 6 à 8 semaines (S2-S3) et à intervalles de 6 mois (S4-S6) sur une période de 28 mois. Les données étaient recueillies et colligées sur un ordinateur Apple II E (Apple, Cupertino CA. U.S.A.) et sur une tablette à commutateur électronique. Les données ont été analysées au moyen d'une analyse de covariance pour mesures répétées avec 2 facteurs par sujet, le jour et l'heure. Résultats: Il y avait une différence statistiquement significative pour 2 mesures cognitives sur 11. Le taux d'erreur associé au test $\mathrm{A}$ (temps de réaction simple) diminuait significativement pour le facteur jour (plusieurs visites) $\mathrm{p}=$ 0.01 . Pour le test $\mathrm{C}$, le taux d'erreur diminuait dans l'après-midi $\mathrm{p}=0.03$. Ce test évaluait l'habilité des sujets à répondre rapidement à un signal tout en ignorant un second signal donné simultanément. L'analyse des données de la covariante a montré que les effets de la SNV sont faibles comparés aux différences initiales et que la fréquence de la stimulation prédit négativement le nombre de fausses erreurs. Les résultats de la stimulation à haute fréquence ont montré moins d'erreurs que la stimulation à basse fréquence $\mathrm{T}=-2.31, \mathrm{p}=0.03$. Conclusion: La stimulation chronique du nerf vague gauche pour le contrôle des crises n'augmente pas les déficits moteurs cognitifs.
\end{abstract}

Can. J. Neurol. Sci. 1997; 24: 226-229

Stimulation of the left vagus nerve has been used as an adjunctive treatment to control intractable complex partial seizures in man. ${ }^{1-9}$ Efficacy studies are necessary to determine the impact of continued chronic stimulation of the left vagus nerve (VNS) on cognitive motor control. Reaction time methodologies are used to assess cognitive motor function and the results have wide application to assessment of activities of daily living.
Reaction time experiments of epileptic subjects who were treated with conventional anticonvulsant drug therapy demonstrated no significant differences between epileptic patients and

\footnotetext{
From the Division of Neurology, McMaster University Medical Centre, Hamilton. RECEIVED JULY 29, 1996. ACCEPTED IN FINAL FORM FEBRUARY 4, 1997.

Reprint requests to: Beverley M. Clarke, Division of Neurology - 4U6, McMaster University Medical Centre, 1200 Main Street W., Hamilton, Ontario, Canada L8N 3Z5
} 
normal controls for simple reaction time tests. ${ }^{10,11}$ However, the response time of the epileptic group was significantly slower than the control group for more complex reaction time tests and epileptic subjects made more errors. Other stimulation studies involving direct stimulation of the anterior thalamic nucleus in epileptic subjects resulted in gradual, steady improvement in pegboard performance and reaction time variability. ${ }^{12}$

Cognitive motor function studies in subjects with intractable complex partial seizures who were receiving electrostimulation of the left vagus nerve showed no significant acute adverse effects which could be attributed to VNS. ${ }^{13,14}$ These studies did show that response times of the epileptic group were much slower than normal controls and older control subjects with Parkinsons disease (Figure 1). The chronic effects (28 months post operatively) of stimulation of the left vagus nerve on cognitive motor response times in subjects with intractable complex partial seizures are reported below.

\section{Methods}

A longitudinal double blinded cross over study, part of a multicenter trial was done to determine the effects of chronic stimulation of the left vagus nerve on seizure control in 8 subjects with complex partial seizures. ${ }^{1-8}$ In addition, subjects were assessed to determine whether there were any adverse effects on cognitive motor function. This paper reports the effects of VNS on cognitive motor control. The project was approved by the Medical Ethics Committees of Chedoke-McMaster Hospitals, Hamilton, Ontario, Canada and was supported by the Michael DeGroote Foundation for research in epilepsy.

Subjects were implanted with a Neurocyberonics pacemaker, Model 100, Cyberonics Inc. Webster, Texas, U.S.A. Complete data sets were available on 6 of the 8 subjects. The reason that 2 subjects had incomplete data sets was that one subject was severely mentally retarded and was unable to concentrate long enough to do all sets of the trials and one subject had severe compliance problems. The six subjects had a mean age of $33 \pm$

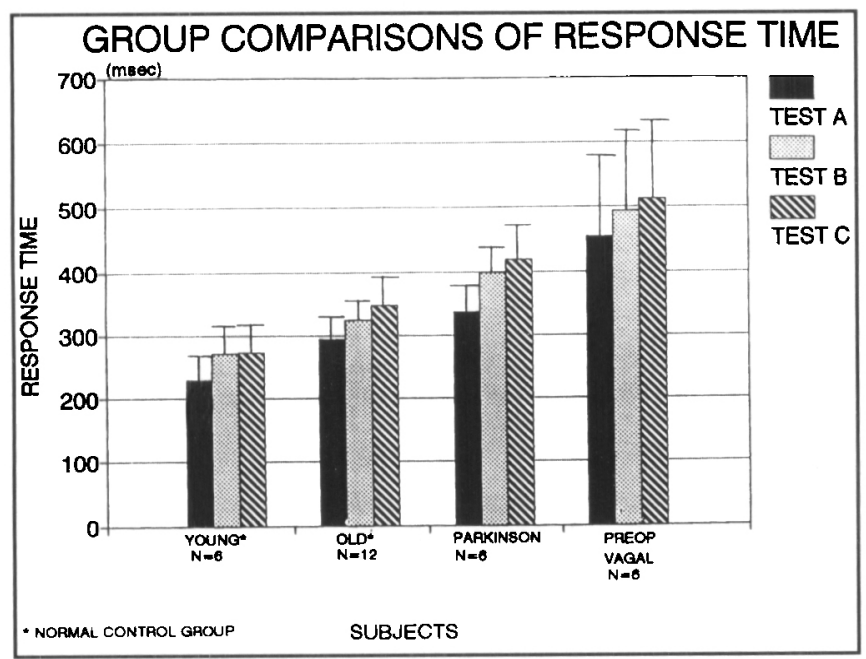

Figure 1: Group comparisons of response time. Young subjects mean age $27.3 \pm 4.48$, Old subjects mean age $68.8 \pm 4.75$, Parkinsonian subjects mean age 67.8 \pm 4.92 , Vagal subjects mean age $33 \pm 9.17$ SD years.
9.17 SD years and five subjects were male. All were on three anticonvulsant medications to control intractable complex partial seizures and all had seizures for more than 20 years. Inclusion criteria were that subjects must have at least 6 seizures/month without more than a 2 week interval between seizures. Exclusion criteria were pregnancy or evidence of other neurological disease. Patients were originally randomized into a high frequency $(30 \mathrm{~Hz}, 500 \mu \mathrm{sec})$ and low frequency stimulation $(1 \mathrm{~Hz}, 130 \mu \mathrm{sec})$ group. After 12 weeks all subjects received high frequency stimulation because it was found that seizure frequency decreased more with high frequency stimulation. ${ }^{1-3,6,8}$ Anticonvulsant drug levels were at therapeutic levels throughout all tests and dosages were not changed.

Subjects were assessed on how quickly they responded to a randomized light signal appearing on an electronic switch pad (test A-reaction time), then to a randomized signal appearing bilaterally (test B-choice reaction time) and finally their ability to respond quickly to one signal while simultaneously ignoring a second signal (test $\mathrm{C}$-inhibition time). All tests were preceded by a set of warning signals indicating that the test was about to begin. The tests varied in complexity, particularly in the amount of attention and strategizing required.

Data were collected and collated using an Apple IIE computer (Apple, Cupertino, CA, USA). The software used was developed at Simon Fraser University, Burnaby, British Columbia, Canada, based on experiments of Donders \& Posner et al. $(1969,1978) .^{15,16}$ Each session (S1-S6) involved assessment at half hour intervals over a 7 hour period. Each test set (test A, B, C) takes a combined time of 10 minutes. Evaluations were done preoperatively (S1) and at 6-8 week intervals (S2-S3) and every 6 months thereafter (S4-S6) over 28 months. There were 6 sessions per subject.

A repeated measures analysis of covariance technique with 2 within subject factors, day, (repeated visits) and time of day (a.m. versus p.m.) was used to compare the mean values of several cognitive outcome measures. The outcome measures were response time, response errors, total errors, premature errors, wrong errors, slow errors and the cost benefit ratio. For each test, there were 54 observations per subject. The time of day factor was calculated by using the first 4 observations of the testing day to create a morning mean. In a similar manner the last 5 observations are components of the afternoon mean value for each variable. The covariate in each individual design was the session 1 pre-implant value. The covariate was defined by the BMDP program $2 \mathrm{VI}$ as one that changes across trials to correspond with the a.m./p.m. divisions for each day of testing. The regression analysis was done for each cognitive measure individually. The set of potential predictors for each measure were session and time of day. The pair-wise comparisons for time of day was a level of 2 and with sessions, the level is 5 (sessions 26). Session 1 was the covariate which changed across trials.

A coefficient of variation (CV) analysis was done in order to compare the variation between the parameters relative to the mean. The calculation is:

$$
\mathrm{CV}=\quad \frac{\text { standard deviation of the test scores }}{\text { mean of the test scores }} \times 100 \%
$$

Because of the indeterminate shelf life of the batteries, the stimulation frequency has to be viewed as a RANDOM EVENT 
rather than a fixed factor in our designs. Therefore, the stimulation frequency, regression analysis was done independently. Seizure frequency was also viewed as a RANDOM EVENT which changes erratically and was not used in our design.

\section{ReSUlts}

Two of eleven cognitive measures showed statistically significant differences between $\mathrm{S} 1$, (pre-operative) assessment and S6, (after 28 months of stimulation). Test A (reaction time), error rate showed a decrease in number of errors over time. The mean number of errors decreased from 1.60 pre-operatively to .82 after 28 months of stimulation. This decline in errors is supported by a statistically significant $F$ value for the covariate $[(F(4,20)=7.61 \mathrm{p}=.05]$. The within subject repeated factor of session was also significant $[F(4,20)=4.28 p=.01]$ but the improvement in performance was not a clear linear progression. Fluctuations in performance can be expected due to the nature of epilepsy and the effect of drug therapy. For test $\mathrm{C}$ (inhibition), error rates declined from morning to afternoon when compared to presurgery rates $[F(1,4)=15.85 \mathrm{p}=.01]$. After stimulation, analysis of results of morning vs. afternoon values showed statistically significant improvement occurring in the afternoon $[F(1,4)=10.41 \mathrm{p}=.03]$. The above errors include whether the responses were too fast, too slow or incorrect for the specific trials. There was no effect for response time for any of the reaction time tests.

In several of the other analyses, the covariate (S1) was found to be statistically significant more often than the within subject repeated factor of session (2 through 6). Since S1 was the baseline measure pre-surgery and the covariate used across the trials, this finding indicates that the effect of vagus nerve stimulation is weak in comparison to the baseline differences among patients and their cognitive functioning. Although the factor of time of day did not yield statistically significant differences in those cases, a close look at the pre-operative morning means compared to the post operative overall morning means makes the improvement over time more apparent. The pre-operative afternoon compared to the post operative overall afternoon means showed a similiar trend.

A multiple regression equation was used to look for variables which influence each cognitive outcome. Only 1 statistically significant predictor was found. The frequency of stimulation negatively predicts the number of wrong errors $\mathrm{T}=-2.31, \mathrm{p}=$ .03. Therefore, with high frequency stimulation, performance resulted in fewer errors than with low frequency stimulation.

Results of the coefficient of variation analyses show (Table 1) that performance is repeatable between sessions. With repeated sessions the variations relative to the mean are very low, indicating that the variance in standard deviation around the mean is fairly small from session to session.

\section{Discussion}

Chronic stimulation of the left vagus nerve showed no adverse effects for simple reaction time, or for the more complex cognitive motor reaction time tests. In fact, improvement was shown in some tests. Error rates decreased significantly

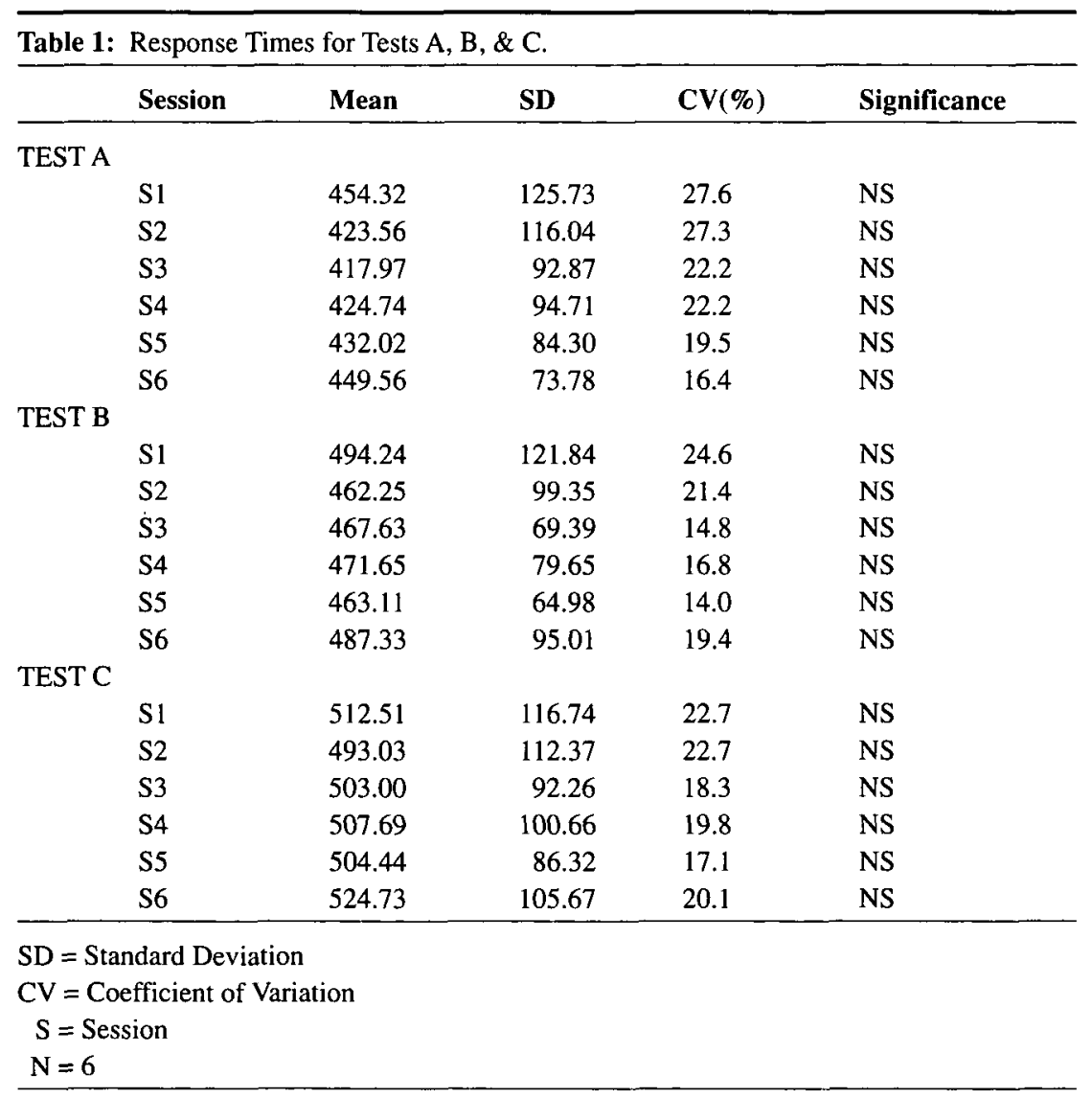




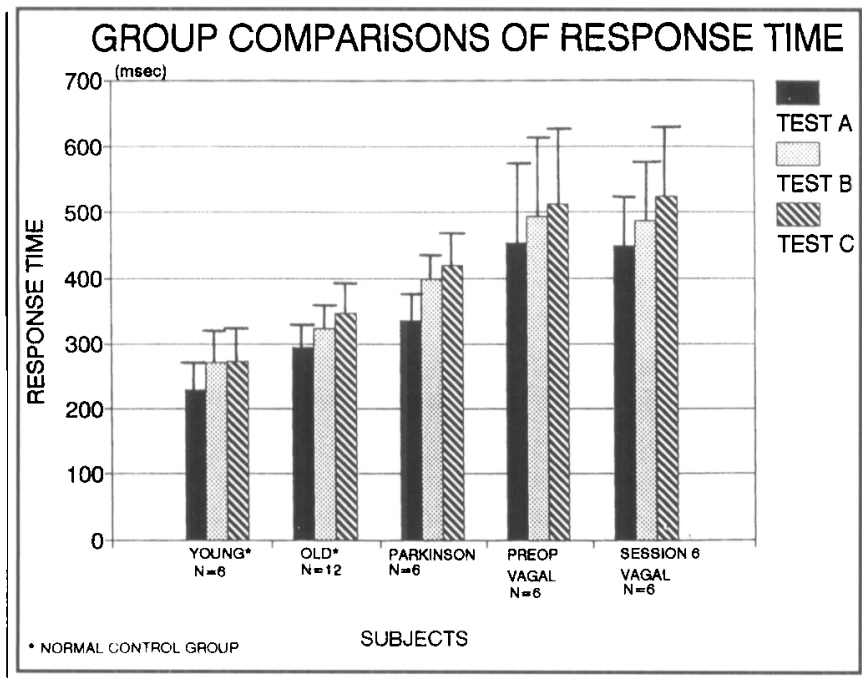

Figure 2: Group comparisons of response time after 21/4 years of stimulation. Young subjects mean age $27.3 \pm 4.48$, Old subjects mean age $68.8 \pm 4.75$, Parkinsonian subjects mean age $67.8 \pm 4.92$, Vagal subjects mean age $33 \pm 9.17 S D$.

over time in Test $\mathrm{A}$, and there was a significant decrease in error rate from morning to afternoon in Test $\mathrm{C}$. Statistical regression analyses showed that the effect of left vagal nerve stimulation on cognitive performance is weak. Any improvement in performance over time is thought to be the result of post-operative stimulation rather than a learning effect. Further, changes are not likely to be due to repeated exposure to the tests because there was not a great improvement or deterioration in performance which would have been the case had subjects simply learned how to perform more proficiently or on the other hand become bored and careless (Figure 2). Using subjects as their own control in this study design is valid because the within subject variance is accounted for in the design. Persistent impairment of cognitive motor control (response time) may be attributed, in part, to the chronic long term effects of anticonvulsant drug therapy and/or the natural history of complex partial seizures. These conclusions are supported by other reports and The Multicenter Holmfrid Study of significant improvement in psychomotor speed after drug withdrawal. ${ }^{17,18}$ Furthermore, phenytoin has been shown to cause more impairment of motor and mental speed than carbamazepine, and phenobarbital has been shown to produce worse results on choice reaction time in healthy adults. ${ }^{19}$ In a study of newly diagnosed patients with epilepsy, phenytoin was shown to have a negative effect on motor speed of the hands. ${ }^{20}$ These effects may be contributing factors affecting the results of our study. Our results clearly show that vagal nerve stimulation to control complex partial seizures does not impair cognitive motor function in subjects with intractable complex partial seizures who are on long term anticonvulsant drug polytherapy.

\section{ACKNOWLEDGEMENTS}

We thank Mary Lou Schmuck, B.A., for assistance with statistical analyses, and Programme for Educational Development, Education Services, McMaster University Medical Centre.

\section{REFERENCES}

1. Anonymous. A randomized controlled trial of chronic vagus nerve stimulation for treatment of medically intractable seizures. The Vagus Nerve Stimulation Study Group. Neurology 1995; 45(2): 224-230.

2. Ben-Menachem E, Manon-Espaillat R, Ristanovic R, et al. First International Vagus Nerve Stimulation Study Group. Vagus nerve stimulation for treatment of partial seizures: 1. A controlled study of effect on seizures. Epilepsia 1994; 35(3): 616626.

3. George R, Salinsky M, Kuzniecky R, et al. First International Vagus Stimulation Study Group. Epilepsia 1994; 35(3) 637-643.

4. Holder LK, Wernicke JF, Tarver WB. Treatment of refractory partial seizures: preliminary results of a controlled study. Pacing Clin Electrophysiol 1992; 15: 1557-1571.

5. Landy HJ, Ramsay RE, Slater J, Casiano RR, Morgan R. Vagus nerve stimulation for complex partial seizures: surgical technique. J Neurosurg 1993; 79(4): 636-637.

6. Michael JE, Wegener K, Barnes DW. Vagus nerve stimulation for intractable seizures: one year follow-up. J Neurosci Nurs 1993; 35(6): 362-366.

7. Neufeld M, Quaknine G, Korczyn. Vagus nerve stimulation for partial seizures. Harefuah $1995 ; 129(1-2): 5-7$.

8. Ramsay RE, Uthman BM, Augustinsson LE, et al. The First International Vagus Stimulation Study Group. Vagus nerve stimulation for treatment of partial seizures: 2 . Safety, side effects and tolerability. Epilepsia 1995; 35(3): 627-636.

9. Uthman BM, Wilder BJ, Penry JK, et al. Treatment of epilepsy by stimulation of the vagus nerve. Neurology 1993; 43; 1338-1345.

10. Alpherts WC, Aldenkamp P. Results of reaction time measurement in patients with epilepsy. Epilepsia 1994; (Suppl. 7): 35 Abstract.

11. Willem CJ, Alpherts \& Albert P, Aldenkamp P. Results of reaction time measurement in patients with epilepsy. Epilepsia 1994; (Suppl. 7) 35: 52.

12. Upton ARM, Cooper IS, Springham M, Amin I. Suppression of seizures and psychosis of limbic system origin by chronic stimulation of anterior nucleus of thalamus. XII Int Symposium of the Fulton Society. "Brain Mechanisms of Emotion". Int J Neurol 1985; (19-20): 223-230.

13. Clarke BM, Upton A, Griffin H, Hudoba P. Balance and cognitive impairment in two epileptic patients before and after vagal nerve stimulation. Pace 1991; 14(1): 77-85.

14. Clarke BM, Upton ARM, Griffin H, Hudoba P. Acute effects of high frequency vagal nerve stimulation on balance and cognitive motor performance in epilepsy: three case study reports. Pace 1992; 15(10): 1608-1613.

15. Donders FC. On the speed of mental processes. In: WG Hoster, ed. and translator. Attention and Performance II. Acta Psychol 1969; 30: 412-431.

16. Posner MI, Nissen MJ, Ogden WC. Attended and unattended processing modes: the role of spatial location. In: HL Pick, IJ Saltzman, eds. Modes of Perceiving and Processing Information. Hillsdale, NJ: Lawrence Erlbaum Associates, Inc., 1978.

17. Aldenkamp AP, Alpherts WCJ, Blennow G, et al. Withdrawal of antiepileptic medication in children-effects on cognitive function: the Multicenter Holmfrid Study. Neurology 1993; 43(1): 41-49.

18. Van Rijckevorsel-Harmant K, Flahaut D, Harman J, de Barsy T. Event-related potentials and cognitive function in epileptic patients. Clin Electroencephalogr 1990; 2: 67-73.

19. Meador KJ, Loring DW, Moore EE, et al. Comparative cognitive effects of phenobarbital phenytoin and valproate in healthy adults. Neurology 1995; 45: 1494-1499.

20. Pulliainen V, Jokelainen $M$. Comparing the cognitive effects of phenytoin and carbamazepine in long-term monotherapy: a twoyear follow-up. Epilepsia 1995; 36: 12: 1195-1202. 